\title{
Low Loss Polycarbonate Polymer Optical Fiber for High Temperature FBG Humidity Sensing
}

\author{
Woyessa, Getinet; Fasano, Andrea; Markos, Christos; Rasmussen, Henrik K.; Bang, Ole
}

Published in:

I E E E Photonics Technology Letters

Link to article, DOI:

10.1109/LPT.2017.2668524

Publication date:

2017

Document Version

Peer reviewed version

Link back to DTU Orbit

Citation (APA):

Woyessa, G., Fasano, A., Markos, C., Rasmussen, H. K., \& Bang, O. (2017). Low Loss Polycarbonate Polymer Optical Fiber for High Temperature FBG Humidity Sensing. I E E E Photonics Technology Letters, 29(7), 575578. https://doi.org/10.1109/LPT.2017.2668524

\section{General rights}

Copyright and moral rights for the publications made accessible in the public portal are retained by the authors and/or other copyright owners and it is a condition of accessing publications that users recognise and abide by the legal requirements associated with these rights.

- Users may download and print one copy of any publication from the public portal for the purpose of private study or research.

- You may not further distribute the material or use it for any profit-making activity or commercial gain

- You may freely distribute the URL identifying the publication in the public portal 


\title{
Low loss polycarbonate polymer optical fiber for high temperature FBG humidity sensing
}

\author{
Getinet Woyessa, Andrea Fasano, Christos Markos, Henrik K. Rasmussen, and Ole Bang
}

\begin{abstract}
We report the fabrication and characterization of a polycarbonate (PC) microstructured polymer optical fiber (mPOF) Bragg grating (FBG) humidity sensor that can operate beyond $100^{\circ} \mathrm{C}$. The $\mathrm{PC}$ preform, from which the fiber was drawn, was produced using an improved casting approach to reduce the attenuation of the fiber. The fiber loss was found reduced by a factor of two compared to the latest reported $\mathrm{PC}$ mPOF [20], holding the low loss record in PC based fibers. PC mPOFBG was characterized to humidity and temperature, and a relative humidity $(\mathrm{RH})$ sensitivity of $7.31 \pm 0.13 \mathrm{pm} / \% \mathrm{RH}$ in the range $10-90 \% \mathrm{RH}$ at $100^{\circ} \mathrm{C}$ and a temperature sensitivity of $25.86 \pm 0.63 \mathrm{pm} /{ }^{\circ} \mathrm{C}$ in the range $20-100{ }^{\circ} \mathrm{C}$ at $90 \% \mathrm{RH}$ were measured.
\end{abstract}

Index Terms - Annealing, Fiber gratings, Humidity measurement, Optical fiber sensors, Plastic optical fiber, Temperature measurement.

\section{INTRODUCTION}

$\mathrm{T}$ HE interest in polymer optical fiber (POF) sensors is steadily increasing because of their low processing temperature, high flexibility in bending, high fracture toughness, ease of handling, and non-brittle nature, which are properties that glass fibers do not have [1]. In addition, POFs have a high elastic strain limit with low Young's modulus and they are biocompatible, which makes them advantageous for a range of strain and bio-sensing applications [2-11]. Some polymers, such as PMMA, are humidity sensitive and strongly absorb water [12-15], while others, such as Topas and Zeonex, have been reported to be insensitive to humidity [16-19]. Therefore, one of the key characteristics of PMMA based POFs is their ability to highly absorb moisture. The moisture absorption leads to a change in the refractive index and size of the fiber, which consequently change the Bragg wavelength [12]. Therefore, PMMA based fiber Bragg gratings (FBGs)

Manuscript received $\mathrm{xxxx}$; revised $\mathrm{xxxx}$; accepted $\mathrm{xxxx}$. Date of publication xxxx, 2016; date of current version xxxx. This work was supported by People Programme (Marie Curie Actions) of the European Union's Seventh Framework Programme (608382); Danish Research Council (FTP) (4184-00359B); Carslberg Foundation (CF14-0825) and Innovation Fund Denmark ( ShapeOCT) (4107-00011A).

Getinet Woyessa, Christos Markos, and Ole Bang are with the Department of Photonics Engineering (DTU Fotonik), Technical University of Denmark, DK-2800 Kgs. Lyngby, Denmark (e-mail: gewoy@fotonik.dtu.dk, chmar@fotonik.dtu.dk and oban@ fotonik.dtu.dk).

Andrea Fasano and Henrik K. Rasmussen are with the Department of Mechanical Engineering, Technical University of Denmark, DK-2800 Kgs. Lyngby, Denmark (e-mail: andfas@mek.dtu.dk and hkra@mek.dtu.dk).

Color versions of one or more of the figures in this letter are available online at http://ieeexplore.ieee.org. Digital Object Identifier xxxx are considered as potential candidates for developing humidity sensors [12-13].

The temperature and relative humidity $(\mathrm{RH})$ operational limits and stability of polymer optical fiber Bragg gratings (POFBGs) strongly dependent on two parameters: the glass transition temperature $\left(\mathrm{T}_{\mathrm{g}}\right)$ and moisture absorbing capability of the fiber material. The temperature operational limit of POFBGs produced from humidity insensitive polymers, such as Topas and Zeonex, relies exclusively upon their $\mathrm{T}_{\mathrm{g}}$ and thus they can reliably operate $15-20{ }^{\circ} \mathrm{C}$ below their $\mathrm{T}_{\mathrm{g}}$ regardless of the surrounding RH level [16-19]. However, this is not the case for other polymers such as PMMA which have high affinity to water. The temperature operational limit of PMMA POFBGs is strongly dependent on the surrounding RH level and vice versa. At ambient or lower RH level, they can operate $15-20{ }^{\circ} \mathrm{C}$ below their $\mathrm{T}_{\mathrm{g}}$. It has been reported that PMMA POFBGs can operate up to $90{ }^{\circ} \mathrm{C}$ at ambient $\mathrm{RH}$ [20]. However, when the surrounding RH is higher than the ambient $\mathrm{RH}$, the temperature operational limit decreases significantly. For instance, when PMMA POFBGs humidity sensors are operated up to $90 \% \mathrm{RH}$, the maximum operational temperature is $75{ }^{\circ} \mathrm{C}$ [15]. This is attributed to the fact that glass transition temperature of PMMA decreases with increasing humidity [21]. So far, characterization for temperature measurement of POFBGs has been carried out using a hot plate or a conventional oven with no control on relative humidity $[20,22]$. It is known that as the temperature of the hot plate or oven increases the corresponding surrounding relative humidity decreases dramatically. To verify this behavior we performed a systematic investigation using an environmental controlled chamber. The chamber was first programmed to have a fixed $\mathrm{RH}$ of $90 \%$ and ambient temperature. Releasing the $\mathrm{RH}$ of the chamber and by increasing the temperature up to $80^{\circ} \mathrm{C}$, it can be clearly seen from Fig. 1 how the RH of the chamber significantly and rapidly decreases and reaching an equilibrium at $1 \% \mathrm{RH}$ in less than 3 hours. Based on this response, we can conclude that similar behavior occurs in a humidity uncontrolled environment such as for example in an open space hot element or oven. At $1 \% \mathrm{RH}, \mathrm{T}_{\mathrm{g}}$ of PMMA is expected to be higher than the one at ambient relative humidity as the water uptake capability will be lower and water acts as a plasticizer for PMMA [21]. Therefore, humidity is a limiting factor in the maximum operating temperature of POFBGs which have strong affinity to water. Similarly, when PMMA POFBGs are used as humidity sensors, the range of operation is highly dependent on the environmental temperature. PMMA mPOFBGs have been operated in the range 10-90\% RH at 
maximum limiting temperature of $75{ }^{\circ} \mathrm{C}$ with no hysteresis [15]. At $90 \% \mathrm{RH}$ and temperature beyond $80^{\circ} \mathrm{C}$, the grating is experiencing a significant degradation and it is unable to operate. Therefore, PMMA based POFBGs can operate beyond $75{ }^{\circ} \mathrm{C}$ provided the corresponding $\mathrm{RH}$ level is lower than $90 \%$.

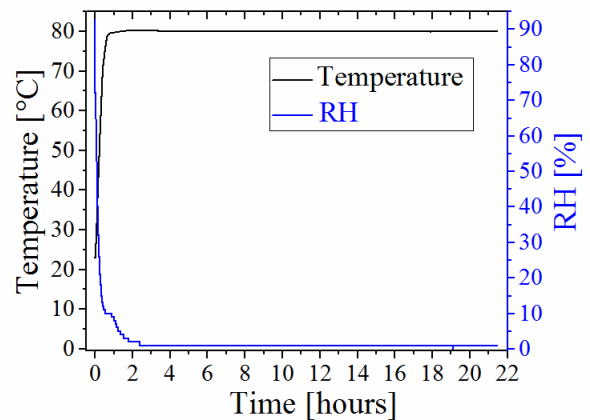

Fig. 1 The humidity response of an oven as the temperature is increasing.

Thus, it is extremely important for different applications to develop POFBG humidity sensors which can fulfill and operate at both high temperatures beyond the operational limit of PMMA POFBGs, and also wide range of relative humidity operation. In this work, we demonstrate for the first time a record low loss mPOFBGs humidity sensor that can operate beyond $90 \% \mathrm{RH}$ and $100{ }^{\circ} \mathrm{C}$ using $\mathrm{PC}$ as the fiber material. Recently, it has been demonstrated that PC mPOFBG can operate up to $125^{\circ} \mathrm{C}$ at ambient relative humidity [23]. The glass transition temperature and water absorption (saturation value) at $23^{\circ} \mathrm{C}$ for different polymer used for the fabrication of $\mathrm{mPOFs}$ is listed in Table I.

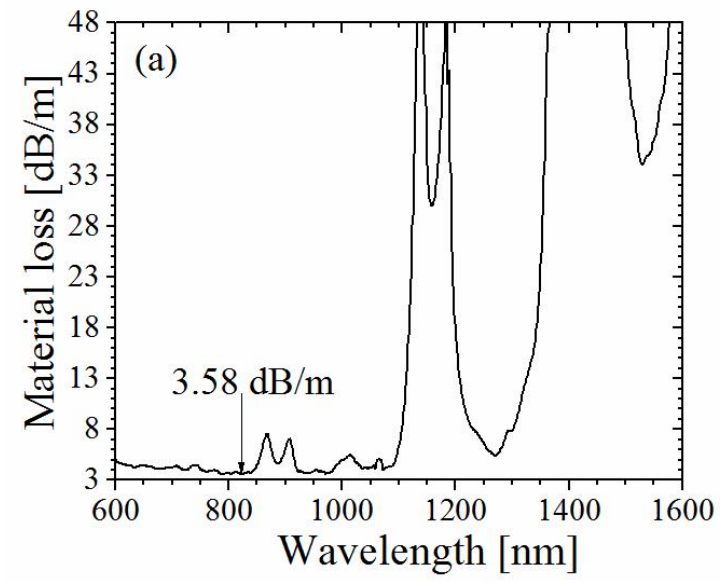

Fig. 2 (a) Bulk material optical loss for the improved PC solid rod. (b) Measured transmission loss of PC mPOF from both old and improved casting methods. Inset: Optical microscope image of the fabricated PC mPOF.

\section{EXPERIMENTS AND RESULTS}

The microstructured fiber used in this report was fabricated inhouse at DTU Fotonik using a drill and draw method described in [23]. However, to reduce the loss of the fiber we used an improved casting approach for the preform production. One of the most crucial factors which define the final fiber loss is perhaps the quality of the cast preform. The casting procedure was optimized with regard to two aspects: drying phase and melting phase. A better water removal was achieved by using an oven with enhanced air circulation. This made it easier for the water trapped inside the plastic pellets to diffuse out during the drying, thereby improving the overall quality of the casting process. The melting phase was extended to remove any possible micro-sized residuals of crystals left in the final preform. Indeed, incomplete melting due to insufficient melting time might lead to the presence of micro-crystals in the core of the cast preform, which would result in higher scattering loss. This can be seen in the visible region in Fig. 2(b), where the gap between old and new fiber transmission losses increases with decreasing wavelength.

TABLE I

POLYMERS GLASS TRANSITION TEMPERATURE AND WATER ABSORPTION (SATURATION VALUE) AT $23^{\circ} \mathrm{C}$

\begin{tabular}{|c|c|c|}
\hline Polymer types & $\begin{array}{c}\text { Glass } \\
\text { transition } \\
\text { temperature }\end{array}$ & $\begin{array}{c}\text { Water absorption } \\
\text { (saturation value) at } \\
23^{\circ} \mathrm{C}\end{array}$ \\
\hline PMMA [24] & $106^{\circ} \mathrm{C}$ & $2.1 \%$ \\
\hline PC [25] & $145^{\circ} \mathrm{C}$ & $0.3 \%$ \\
\hline TOPAS5013S-04 [26] & $134^{\circ} \mathrm{C}$ & $<0.01 \%$ \\
\hline Zeonex 480R [27] & $138^{\circ} \mathrm{C}$ & $<0.01 \%$ \\
\hline
\end{tabular}

The bulk material loss of the PC polymer and the PC mPOFs losses are shown in Fig. 2(a) and 2(b), respectively. The minimum fiber propagation loss was found to be $\sim 4.06 \mathrm{~dB} / \mathrm{m}$ at $819 \mathrm{~nm}$ and at this wavelength the material loss is $\sim 3.58$ $\mathrm{dB} / \mathrm{m}$. It should be emphasized that the fiber loss was reduced by a factor of two compared to the first fabricated PC mPOF [23], holding thus the record in PC POFs loss. Both the cane and the fiber have been drawn at $170^{\circ} \mathrm{C}$ and $10.5 \mathrm{MPa}$ drawing stress. The final core and cladding diameter of the fabricated fiber are $10 \mu \mathrm{m}$ and $125 \mu \mathrm{m}$, respectively. The average size of the holes diameter and the pitch size are 2.5

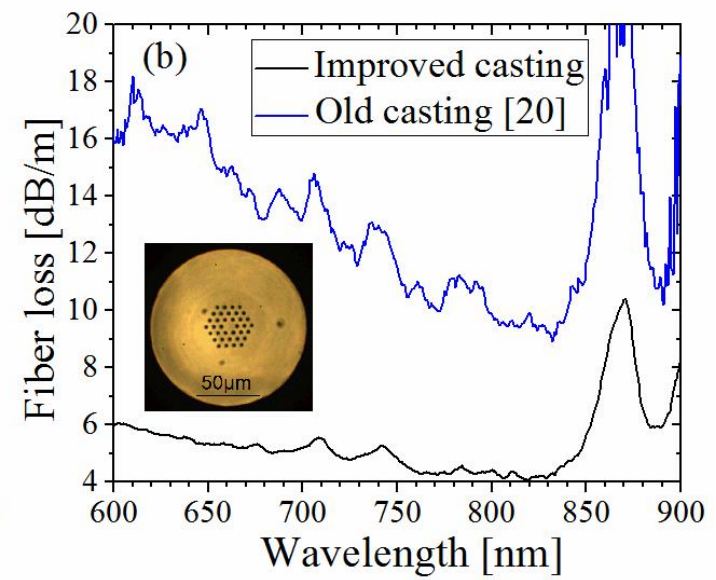

$\mu \mathrm{m}$ and $6.25 \mu \mathrm{m}$, respectively. The hole to pitch ratio is 0.4 ensuring that the fiber is endlessly single mode [28]. A microscope image of the PC $\mathrm{mPOF}$ end facet, which was cleaved with a custom made cleaver at a temperature of $80^{\circ} \mathrm{C}$ of both blade and fiber [29], is shown as an inset in Fig. 2(b).

A fiber Bragg grating was first inscribed in the fabricated PC $\mathrm{mPOF}$. The phase mask writing technique was used for the FBG inscription while the detailed experimental setup can be found in [30]. The phase mask used for grating inscription has a uniform period of $572.4 \mathrm{~nm}$ and the writing laser was a 325 $\mathrm{nm} \mathrm{HeCd} \mathrm{CW} \mathrm{UV} \mathrm{laser.} \mathrm{We} \mathrm{used} \mathrm{only} 5 \mathrm{~mW}$ for the 
inscription of the grating. The grating had a length of $2 \mathrm{~mm}$ and the Bragg wavelength was located at $892.24 \mathrm{~nm}$ with reflection strength of $30 \mathrm{~dB}$ and a full width half maximum of $0.92 \mathrm{~nm}$. The PC mPOFBG was then annealed at $125^{\circ} \mathrm{C}$ for 36 hours in a conventional oven without humidity control. The new Bragg wavelength after annealing was blue shifted to $880.19 \mathrm{~nm}$. To be sure that the PC mPOFBG was properly annealed for humidity sensing operation up to $90 \% \mathrm{RH}$ and at high temperatures, we further annealed it in the climate chamber at $90 \% \mathrm{RH}$ and $100{ }^{\circ} \mathrm{C}$ for 6 hours, as high humidity has been shown to strongly assist the annealing of PMMA POFBGs [15]. For this, the PC mPOFBG was connectorized [31], and placed in a climate chamber (CLIMACELL, MMM Group). A supercontinuum source (SuperK Compact, NKT Photonics) has been used as the broadband light source and a spectrometer (CCS175 - Compact Spectrometer, Thorlabs) has been used to continuously track and record the grating during annealing in the climate chamber. This additional annealing did not lead to any further permanent blue shift, indicating that the POFBG was indeed properly annealed for operation at temperatures and relative humidity levels of $100{ }^{\circ} \mathrm{C}$ and $90 \%$ $\mathrm{RH}$, respectively. The normalized Bragg reflection spectrum of the PC mPOFBG at $90 \% \mathrm{RH}$ and $100^{\circ} \mathrm{C}$ is shown as an inset in Fig. 3(b).

After the annealing process, the humidity response of the PC mPOFBG sensor was measured at three different temperatures: $25^{\circ} \mathrm{C}, 50^{\circ} \mathrm{C}$ and $100^{\circ} \mathrm{C}$, in the interval of $10-90$ $\% \mathrm{RH}$. For each temperature level, the humidity measurement has been done first by increasing the RH from $10 \%$ to $90 \%$, with step of $10 \%$ and then decreasing it from $90 \%$ to $10 \%$ with $10 \%$ step. For both cases, the chamber was programmed to change the $\mathrm{RH}$ in a minute and then to maintain stable the environmental conditions for 45 mins. The response of the PC mPOFBG, for both increasing and decreasing relative humidity at $100^{\circ} \mathrm{C}$, is shown in Fig. 3(a). Fig. 3(b) shows the humidity response at $100^{\circ} \mathrm{C}$ where each measurement point was taken at the end of the 45 mins stabilization period. The humidity sensitivity at $100^{\circ} \mathrm{C}$ was $7.31 \pm 0.13 \mathrm{pm} / \% \mathrm{RH}$ (Rsquared of 0.998), for both increasing and decreasing relative humidity. The corresponding humidity sensitivities at $25{ }^{\circ} \mathrm{C}$ and $50{ }^{\circ} \mathrm{C}$ were measured to be $7.35 \pm 0.05 \mathrm{pm} / \% \mathrm{RH}$ and $7.19 \pm 0.11 \mathrm{pm} / \% \mathrm{RH}$, respectively. These sensitivity figures confirm that the humidity response of PC mPOFBG is unaffected by temperature, and this is due to the fact that the grating was adequately annealed.

We have also measured the temperature sensitivity at two different RH levels: $50 \%$ and $90 \% \mathrm{RH}$ in the range from 20 to $100{ }^{\circ} \mathrm{C}$. For each $\mathrm{RH}$ level, the temperature measurement was first performed from $20^{\circ} \mathrm{C}$ up to $100^{\circ} \mathrm{C}$, with a $10^{\circ} \mathrm{C}$ step and then decreasing it back to $20^{\circ} \mathrm{C}$ with the same step. For both cases, the chamber was programmed to change the temperature in 10 mins and then to maintain the environmental conditions stable for 45 mins. The response of the PC mPOFBG for both increasing and decreasing temperature at $90 \% \mathrm{RH}$ is shown in Fig. 4(a). Fig. 4(b) shows the temperature response at $90 \% \mathrm{RH}$ where each measurement
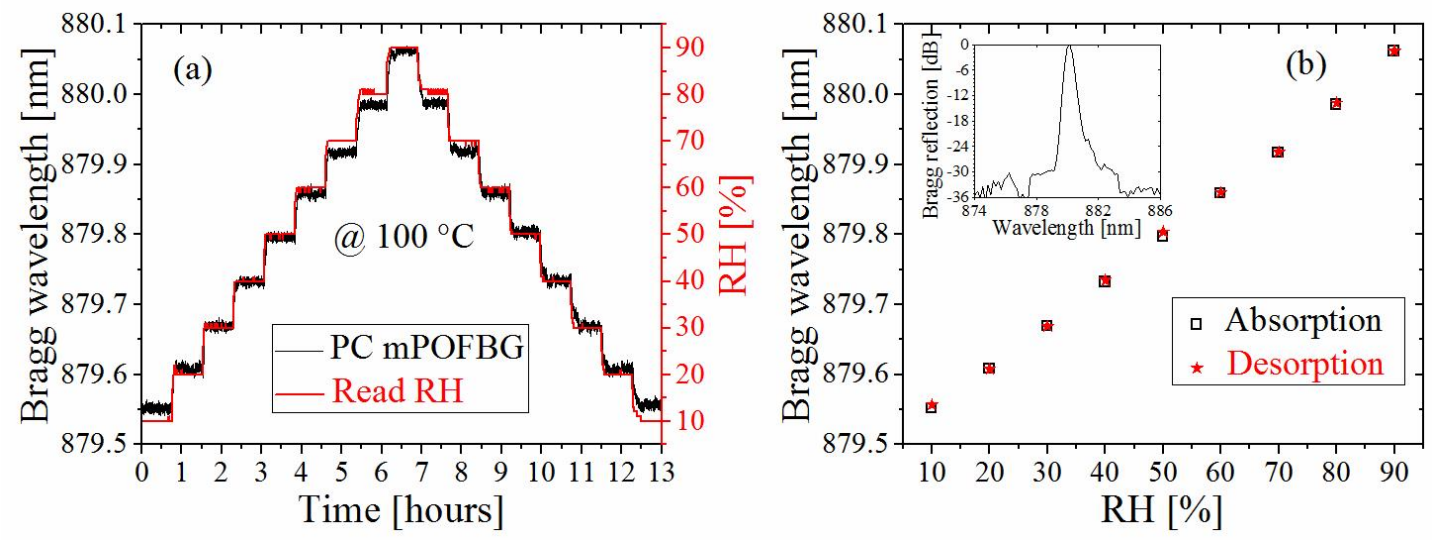

Fig. 3. (a) Measured humidity response at $100{ }^{\circ} \mathrm{C}$ of the PC mPOFBG. (b) Corresponding stabilized humidity response of the PC mPOFBGs at $100^{\circ} \mathrm{C}$. Inset: Normalized Bragg reflection spectrum of the PC mPOFBG.
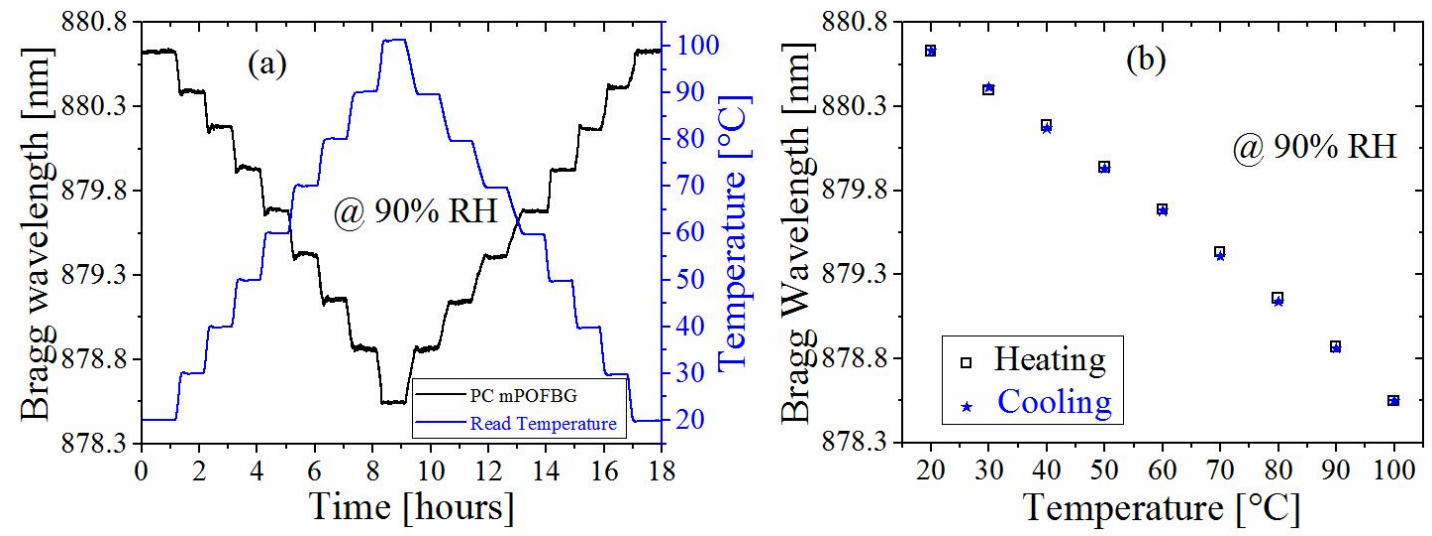

Fig. 4. (a) Measured temperature response at $90 \%$ RH of the PC mPOFBG. (b) Corresponding stabilized temperature response of the PC mPOFBGs at $90 \% \mathrm{RH}$. 
point was taken at the end of the 45 mins for the stabilization period. The temperature sensitivity at $90 \% \mathrm{RH}$ was $25.86 \pm 0.63 \mathrm{pm} /{ }^{\circ} \mathrm{C}$. The corresponding sensitivity at $50 \% \mathrm{RH}$ was $25.62 \pm 0.56 \mathrm{pm} /{ }^{\circ} \mathrm{C}$. No hysteresis was also observed during the temperature characterization, further confirming the fact that the grating was properly annealed.

\section{CONCLUSION}

We have developed and characterized a polycarbonate based mPOFBG humidity sensor that can operate beyond $100{ }^{\circ} \mathrm{C}$ in the relative humidity range $10-90 \%$. The mPOF preform was made by using an improved casting method and the measured loss was found to be two times smaller than the hitherto. The sensor gave a RH sensitivity of $7.31 \pm 0.13 \mathrm{pm} / \%$ $\mathrm{RH}$ in the range $10-90 \% \mathrm{RH}$ at $100{ }^{\circ} \mathrm{C}$ and a temperature sensitivity of $25.86 \pm 0.63 \mathrm{pm} /{ }^{\circ} \mathrm{C}$ in the range $20-100{ }^{\circ} \mathrm{C}$ at 90 $\%$ RH.

The humidity sensitivities of our PMMA mPOFBGs and TOPAS step index POFBGs at $850 \mathrm{~nm}$ are $45 \mathrm{pm} / \% \mathrm{RH}$ and $0.45 \mathrm{pm} / \% \mathrm{RH}$, respectively. Thus the humidity sensitivity of PC mPOFBGs is 6 times smaller than PMMA mPOFBG and 16 times larger than TOPAS POFBGs which are basically humidity insensitive. However, PC mPOFBG humidity sensors can operate up to $90 \% \mathrm{RH}$ at a temperature $25^{\circ} \mathrm{C}$ higher than the maximum operational limit of PMMA mPOFBGs. The temperature sensitivity of PC mPOFBGs is more than a factor of two larger than that of PMMA mPOFBGs. At ambient relative humidity PC mPOFBGs can operate up to $125^{\circ} \mathrm{C}$ while PMMA mPOFBG can only be operated up to $90{ }^{\circ} \mathrm{C}$. Thus, PC mPOFBGs humidity sensors can be used in several different applications areas where humidity measurement at high temperature is required such as in industry for ceramic driers, in domestic electric appliance for microwave oven and in agriculture for thermo-hygrostatic chamber [32].

\section{REFERENCES}

[1] D. J. Webb, "Fiber Bragg grating sensors in polymer optical fibers," Meas. Sci. Technol., vol. 26, no. 9, p. 092004, 2015.

[2] H. Dobb, D. J. Webb, K. Kalli, A. Argyros, M. C. J. Large, and M. A. van Eijkelenborg, "Continuous wave ultraviolet light-induced fiber Bragg gratings in few and single mode microstructured polymer optical fibers," Opt. Lett., vol. 30, no. 24, pp. 3296-3298, 2005.

[3] I. P. Johnson, W. Yuan, A. Stefani, K. Nielsen, H. K. Rasmussen, L. Khan, D. J. Webb, K. Kalli, and O. Bang, "Optical fiber Bragg grating recorded in Topas cyclic olefin copolymer," Electron. Lett. vol. 47, no.4, pp.271-272, 2011.

[4] A. Stefani, S. Andresen, W. Yuan, N. Herholdt-Rasmussen, and O. Bang, "High sensitivity polymer optical fiber Bragg grating based accelerometer," IEEE Photon. Technol. Lett., vol. 24, no. 9, pp. 763$765,2012$.

[5] R. Oliveira, L. Bilro, R. Nogueira, "Bragg gratings in a few mode microstructured polymer optical fiber in less than 30 s," Opt. Express, vol.23, no.8, pp.10181-10187, 2015.

[6] A. Lacraz, M. Polis, A. Theodosiou, C. Koutsides, and K. Kalli, "Femtosecond Laser Inscribed Bragg Gratings in Low Loss CYTOP Polymer Optical Fiber," IEEE Photon. Technol. Lett. vol 27, no.7, pp.693-696, 2015.

[7] J. Jensen, P. Hoiby, G. Emiliyanov, O. Bang, L. Pedersen, and A. Bjarklev, "Selective detection of antibodies in microstructured polymer optical fibers," Opt. Express, vol. 13, no. 15, pp. 5883-5889, 2005.

[8] G. Emiliyanov, J. B. Jensen, O. Bang, P. E. Hoiby, L. H. Pedersen, E. M. Kjaer, and L. Lindvold, "Localized biosensing with Topas microstructured polymer optical fiber," Opt. Lett., vol. 32, no. 5, pp. 460-462, 2007.

[9] C. Markos, W. Yuan, K. Vlachos, G. E. Town, and O. Bang, "Label free biosensing with high sensitivity in dualcore microstructured polymer optical fibers," Opt. Express, vol .19, no. 8, pp. 7790-7798, 2011.

[10] H.U. Hassan, K. Nielsen, S. Aasmul, and O. Bang, "Polymer optical fiber compound parabolic concentrator tip for enhanced coupling efficiency for fluorescence based glucose sensors", Bio. Opt. Express, vol. 12, no. 2, pp. 5008-5020, 2015.

[11] C. Broadway, D. Gallego, G. Woyessa, A. Pospori, G. Carpintero, O. Bang, K. Sugden, and H. Lamela, "Fabry-Perot microstructured polymer optical fiber sensors for opto-acoustic endoscopy", Proc. SPIE, vol. 9531, p. 953116, 2015.

[12] H. G. Harbach, "Fiber Bragg gratings in polymer optical fibers," $\mathrm{PhD}$ Thesis, EPFL, Lausanne, 2008.

[13] C. Zhang, W. Zhang, D. J. Webb, and G. D. Peng, "Optical fiber temperature and humidity sensor," Electron. Lett., vol. 46, no. 9, pp. 643-644, 2010.

[14] C. Zhang, X. Chen, D. J. Webb, and G. D. Peng, "Water detection in jet fuel using a polymer optical fiber Bragg grating," Proc. SPIE, vol. 7503, p. $750380,2009$.

[15] G. Woyessa, K. Nielsen, A. Stefani, C. Markos and O. Bang, "Temperature insensitive hysteresis free highly sensitive polymer optical fiber Bragg grating humidity sensor", Opt. Express, vol. 24, no. 2, pp. 1206-1213, 2016.

[16] W. Yuan, L. Khan, D. J. Webb, K. Kalli, H. K. Rasmussen, A. Stefani, and O. Bang, "Humidity insensitive Topas polymer fiber Bragg grating sensor," Opt. Express, vol 19, no. 20, pp. 19731-19739, 2011.

[17] C. Markos, A. Stefani, K. Nielsen, H. K. Rasmussen, W. Yuan, and O. Bang, "High-Tg Topas microstructured polymer optical fiber for fiber Bragg grating strain sensing at 110 degrees, " Opt. Express, vol. 21, no 4, pp. 4758-4765, 2013.

[18] G. Woyessa, A. Fasano, A. Stefani, C. Markos, K. Nielsen, H. K. Rasmussen and O. Bang, "Single mode step-index polymer optical fiber for humidity insensitive high temperature fiber Bragg grating sensors", Opt. Express, 24, no. 2, pp. 1253-1260, 2016.

[19] G. Woyessa, A. Fasano, C. Markos, A. Stefani, H. K. Rasmussen, and O. Bang, "Zeonex microstructured polymer optical fiber: fabrication friendly fibers for high temperature and humidity insensitive Bragg grating sensing," Opt. Mater. Express, vol. 7, no. 1, pp. 286-295, (2017).

[20] K. E. Carroll, C. Zhang, D. J. Webb, K. Kalli, A. Argyros, and M. C. J. Large, "Thermal response of Bragg gratings in PMMA microstructured optical fibers," Opt. Express, vol.15, no.14, pp. 8844-8850, 2007.

[21] L. S. A. Smith and V. Schmitz, "The effect of water on the glass transition temperature of poly(methyl methacrylate), " Polymer vol. 29 no. 10 , pp. $1871-1878,1988$.

[22] H.Y.Liu, G.D.Peng, and P.L.Chu, "Thermal tuning of polymer optical fiber bragg gratings," IEEE Photon.Technol. Lett. Vol.13, no.8, pp. 824826, 2001.

[23] A. Fasano, G. Woyessa, P. Stajanca, C. Markos, A. Stefani, K. Nielsen, H. K. Rasmussen, K. Krebber, and O. Bang, "Fabrication and characterization of polycarbonate microstructured polymer optical fibers for high-temperature-resistant fiber Bragg grating strain sensors" Opt. Mater. Express, vol. 6, no. 2, pp. 649-659, 2016.

[24] http://www.gehrplastics.com/pmma-acrylic.html

[25] http://www.plastics.covestro.com/en/Products/Makrolon/ProductList/20 1305212210/Makrolon-LED2245

[26] http://www.topas.com/sites/default/files/TDS 5013S04_english\%20units_0.pdf

[27] http://www.zeonex.com/optics.aspx\#techdata

[28] T. A. Birks, J. C. Knight, and P. St.J. Russell, "Endlessly single-mode photonic crystal fiber," Opt. Lett., vol. 22, no. 13, pp. 961-963, 1997.

[29] A. Stefani, K. Nielsen, H. K. Rasmussen, and O. Bang, "Cleaving of Topas and PMMA microstructured polymer optical fibers: Core-shift and statistical quality optimization," Opt. Commun., vol. 285, no. 7, pp. 1825-1833, 2012.

[30] I.-L. Bundalo, K. Nielsen, C. Markos, and O. Bang, "Bragg grating writing in PMMA microstructured polymer optical fibers in less than 7 minutes," Opt. Express, vol. 22, no. 5, pp. 5270-5276, 2014.

[31] A. Abang and D. J. Webb, "Demountable connection for polymer optical fiber grating sensors," Opt. Eng., vol. 51, no. 8, p. 080503-1, 2012.

[32] N.Yamazoe and Y.Shimizu, "Humidity sensors: Principles and Applications, sensors and actuators," vol. 10, no.3-4, 379-398, 1986. 